\title{
Novas Tecnologias e Educação Matemática ${ }^{1}$
}

\section{Adriana Justin Cerveira Kampff** José Carlos Machado*** Patrícia Cavedini*****}

Resumo. Este artigo aborda, de maneira sintética, a fundamentação teórica, os ambientes explorados e algumas experiências de projetos vinculados à aprendizagem matemática em ambientes informatizados. Assim, é interesse dos pesquisadores discutir questões ligadas a como construir conhecimento matemático significativo mediante a incorporação de novas tecnologias no cotidiano escolar. Esse estudo, ora descrito, baseia-se em reflexões realizadas a partir do trabalho com alunos de graduação em Licenciatura em Matemática, em projetos em nível de Especialização e na aplicação prática em escolas.

Palavras-chaves: Novas Tecnologias e Educação Matemática, Softwares Educacionais.

\section{New Technologies and Mathematical Education}

Abstract. This article approaches, in synthetic way, the theory, the tools and some experiences of projects about mathematical learning in digital spaces. Thus, it is interest of the researchers to study questions as how to construct significant mathematical knowledge by the incorporation of new technologies in the school. This paper is based on workshops with students of graduation in Mathematics, projects in pos-graduation and the practical application in schools.

Key-words: New Technologies and Mathematical Education, Educational Software.

\section{Introdução}

Todos reconhecem o papel fundamental das instituições escolares no desenvolvimento intelectual, social e afetivo do indivíduo. Assim, em uma sociedade de bases tecnológicas, com mudanças contínuas, em ritmo acelerado, não é mais possível ignorar as alterações que as tecnologias da informação e da comunicação (TICs) provocam na forma como as pessoas vêem e apreendem o mundo, bem como desprezar o potencial pedagógico que tais tecnologias apresentam quando incorporados à educação. Já é consenso que o computador é um instrumento valioso no processo de ensino e de aprendizagem e, portanto, cabe à escola utilizá-lo de forma coerente com uma proposta pedagógica atual e consistente.

É importante contribuir para que o aluno transforme seus pensamentos, desenvolva atividades criativas, compreenda conceitos, reflita sobre eles e, conseqüentemente, crie novos significados. De nada adianta ter-se computadores de última geração e programas moderníssimos, caso não se saiba como utilizá-los. Perrenoud (2000) destaca como uma das dez competências fundamentais do professor a

\footnotetext{
${ }^{1}$ Artigo apresentado no X Workshop de Informática na Escola, junto ao XXIII Congresso da Sociedade Brasileira de Computação, Bahia, Julho-2004.

** Bacharel em Informática, Mestre em Ciência da Computação, Doutoranda do PGIE, Professora da Faculdade de Informática - Universidade Luterana do Brasil e do Colégio Marista Nossa Senhora do Rosário,adriana@ rosario.com.br.

**** Licenciado em Matemática, Especialista em Informática na Educação, Professor do Colégio Marista Nossa Senhora do Rosário, zecarlos@ rosario.com.br.

***** Bacharel em Administração com Ênfase em Análise de Sistemas, Especialista em Informática na Educação, Professora do Colégio Marista Nossa Senhora do Rosário, patricia@ rosario.com.br.

V.2 $\mathrm{N}^{\circ} 2$, Novembro, 2004
} 
de conhecer as possibilidades e dominar os recursos computacionais existente, cabendo ao professor atualizar-se constantemente, buscando novas práticas educativas que possam contribuir para um processo educacional qualificado. Nesse contexto, o professor torna-se indispensável, tornando-se orientador do processo de aprendizagem, podendo dispor dos meios computacionais para atender aos alunos de forma diversificada, de acordo com suas necessidades.

Nessa perspectiva, destacam-se, a seguir, algumas reflexões e projetos desenvolvidos vinculados à Educação Matemática.

\section{Conhecimento Matemático}

Como se dá o conhecimento matemático? Certamente, essa é a questão-chave a ser discutida, pois a forma como o professor desencadeia suas ações pedagógicas está impregnada pela concepção que tem sobre esse tema.

Um dos maiores problemas na educação decorre do fato que muitos professores consideram os conceitos matemáticos como objetos prontos, não percebendo que estes conceitos devem ser construídos pelos alunos. De alguma maneira os alunos devem vivenciar as mesmas dificuldades conceituais e superar os mesmos obstáculos epistemológicos encontrados pelos matemáticos. Solucionando problemas, discutindo conjeturas e métodos, tornando-se conscientes de suas concepções e dificuldades, os alunos sofrem importantes mudanças em suas idéias [Vergnaud apud Gravina e Santarosa, 1998].

É necessário repensar o ensino e a aprendizagem, colocando-se numa postura de professor inovador, criando situações significativas e diferenciadas, cabendo propiciar diferentes situações "problemas" ao educando. O aluno precisa ser motivado a envolver-se ativamente nesse processo, construindo o seu conhecimento a partir de múltiplas interações. O professor de matemática deve organizar um trabalho estruturado através de atividades que propiciem o desenvolvimento de exploração informal e investigação reflexiva e que não privem os alunos nas suas iniciativas e controle da situação. $\mathrm{O}$ professor deve projetar desafios que estimulem o questionamento, a colocação de problemas e a busca de solução. Os alunos não se tornam ativos aprendizes por acaso, mas por desafios projetados e estruturados, que visem à exploração e investigação [Richards apud Gravina e Santarosa, 1998].

Segundo Gravina e Santarosa (1998), a aprendizagem da Matemática depende de ações que caracterizem o "fazer matemática": experimentar, interpretar, visualizar, induzir, conjecturar, abstrair, generalizar e enfim demonstrar. Quando o aluno coloca-se como sujeito ativo, investigando, explorando, orientado por um professor preparado para colocar-se na postura de mediador, a formalização e a concretização mental de conceitos tratam-se, simplesmente, de uma consequiência do processo.

A partir das reflexões acima, apresenta-se a seguinte questão: é possível utilizar ambientes informatizados como espaços propiciadores de atividades que permitam aos alunos apropriarem-se de idéias matemáticas profundas e significativas?

\section{Espaços Informatizados de Aprendizagem}

Segundo Perrenoud (1999), por parte do professor, supõe-se que tenha competência para criar situações desafiadoras, utilizando recursos didáticos variados, até mesmo aqueles que tenham sido desenvolvidos para outros fins - destaca, nesse contexto, os softwares educacionais e os aplicativos de uso geral, já incorporados no cotidiano de várias tarefas intelectuais. Para que ambientes de aprendizagem baseado em computadores venham a possibilitar ganhos pedagógicos é necessário que sejam realizadas atividades fundamentais no processo de desenvolvimento do conhecimento. 
Valente (1997) destaca que o professor, em consonância com uma proposta pedagógica construtivista sócio-interacionista, deve compreender o significado do processo de aprendizagem através da construção do conhecimento, ter pleno domínio do conteúdo que está sendo abordado e conhecer as possibilidades dos softwares utilizados para, então, poder acompanhar o aluno nesse ambiente e intervir adequadamente quando se fizer necessário. Dependendo do ambiente informatizado escolhido, o professor pode rever o caminho trilhado pelo aluno e, assim, identificar em que momento ele se afastou do objetivo pretendido, discutindo com o aluno o que o levou a fazer tais escolhas e o ajudando a repensá-las e, assim, definir novos rumos.

"O uso do computador permite a realização do ciclo descrição-execuçãoreflexão-depuração-descrição, no qual novos conhecimentos podem ser adquiridos na fase da depuração. Quando uma determinada idéia não produz os resultados esperados, ela deve ser burilada, depurada ou incrementada com novos conceitos ou novas estratégias. Esse incremento constitui novos conhecimentos, que são construídos pelo aluno." [Valente, 1999]

O papel dos recursos utilizados é de dar suporte aos objetos matemáticos e as ações mentais dos alunos, favorecendo os processos inerentes à construção do conhecimento matemático e ao desenvolvimento de estruturas cognitivas, fundamentais na aprendizagem da Matemática.

Segundo Herbenstreint [apud Gravina e Santarosa, 1998], "o computador permite criar um novo tipo de objeto - os objetos 'concreto-abstratos'. Concretos porque existem na tela do computador e podem ser manipulados; abstratos por se tratarem de realizações feitas a partir de construções mentais”.

Idealmente, a escolha de softwares educacionais para a aprendizagem da Matemática deve ser pautada na busca de ambientes que permitam ao aluno [Gravina e Santarosa, 1998]:

Expressão: isto é, descrever, de acordo com a linguagem do ambiente, suas idéias, exteriorizando a concretização de suas construções mentais. De acordo com as ações do aluno, uma representação é visualizada, servindo de base para a reflexão sobre suas concepções (o resultado obtido é o esperado?) e permitindo revê-las, sempre que isto se fizer necessário.

Exploração: parte-se de modelos prontos sobre os quais o aluno vai interagir, manipulando-os, buscando compreendê-los, estabelecendo relações e construindo conceitos. Diferentemente da representação de um objeto matemático com lápis e papel, na tela do computador é possível alterar diretamente representações de tais objetos, buscando fazê-los variar e, a partir de tais variações, abstrair a invariância.

Com o intuito de compreender-se melhor o potencial pedagógico dos recursos oferecidos pela Informática, encontram-se, na seqüência, reflexões sobre o tipo de abordagem educacional que alguns programas proporcionam. Busca-se, ainda, discutir as aplicações práticas dos pontos destacados, relatando-se alguns projetos desenvolvidos em escola.

\section{A Linguagem Logo \\ 4.1 Reflexões iniciais}

A linguagem de programação Logo, resultado do trabalho da equipe conduzida por Seymour Papert no Massachusetts Institute of Technology (MIT), no final dos anos 60 , princípio dos anos 70, tem passado por altos e baixos de popularidade em diversos países, mas não deixou de evoluir [Papert, 1985]. A "linguagem da tartaruga", como é popularmente conhecida, difundiu-se nas escolas de todo o mundo, não só como a melhor iniciação à programação, mas também como uma forma diferente de encarar a Informática na Educação. 
A origem da palavra Logo deriva do grego Logos, que significa palavra/razão/argumento. E, ao contrário de muitas outras linguagens pensadas para a programação de computadores, Bossuet [apud Papert, 1985] coloca que Logo designa ao mesmo tempo uma teoria de aprendizagem, uma linguagem de comunicação e um conjunto de unidades materiais que permite demonstrar os processos mentais empregados por um indivíduo para resolver um problema, num contexto de ação sobre o mundo exterior. Acrescenta, ainda, que "a teoria do conhecimento adotada por Logo faz uma síntese entre a concepção de Piaget sobre o desenvolvimento da criança e o estudo, em inteligência artificial, do problema do pensamento. A criança não é mais um objeto a ser modelado, educado. Ela torna-se sujeito". Propõe-se, então, propiciar às crianças a interação com essa linguagem, para que elas também possam pensar mais concretamente a respeito dos processos mentais, pois a habilidade de articular os processos do pensamento dá a chance de melhorá-los.

O Logo é um recurso flexível que permite a construção de programas, o teste de hipóteses, a manipulação de variáveis e a reflexão sobre os próprios processos de aprendizagem, centrado no aluno, no desenvolvimento de estratégias de raciocínio, na conscientização do próprio processo de aprendizagem, na pedagogia de projetos - leva o sujeito a perceber a diferença entre "saber alguma coisa" (ler) "e ser capaz de fazer (criar) alguma coisa" (escrever) - e na aprendizagem cooperativa.

Quando o programa é executado e não fornece a resposta esperada, o aluno analisa seus erros, refletindo sobre o processo, desde a situação-problema como um todo até a descrição realizada, numa atividade de compreensão e depuração. Conforme Papert (1985), "a melhor aprendizagem ocorre quando o aprendiz assume o comando".

A metodologia de Papert (1985) propõe que a iniciação à linguagem de diálogo com as máquinas computadorizadas seja através de atividades lúdicas. $\mathrm{O}$ diálogo com a tartaruga leva a criança aos poucos a aprender as noções básicas do sistema Logo; de forma prática e utilitária as crianças se apropriam de estruturas complexas.

Assim, trabalhar com a "tartaruga" mobiliza a experiência e o prazer com o movimento. Toda essa experiência faz uso de um campo de conhecimento bem familiar à criança, a "geometria do corpo", como ponto de partida para o desenvolvimento de conexões com a geometria formal [Papert, 1985]. É possível observar-se essas conexões nas experiências descritas em Cavedini (2002).

A geometria é um excelente instrumento para estimular o raciocínio lógico. No trabalho com a linguagem Logo, o primeiro passo do aluno é observar a realidade, podendo retratá-la por meio de desenhos e construção de sólidos. Através dessas representações, supõe-se que ele passe a se confrontar com a realidade e se instrumentalize para analisá-la e compreendê-la.

No ambiente Logo, a criança está no controle - a criança programa o computador. E ao ensinar o computador a "pensar" a criança embarca numa exploração sobre a maneira como ela própria pensa. Pensar sobre modos de pensar faz da criança um epistemólogo, uma experiência que poucos adultos tiveram [Papert, 1994].

A linguagem Logo, assim, tem características que permitem que o sujeito aja, propondo soluções; reaja, modificando-as; e conserve os resultados de suas experiências.

\subsection{Experiências}

As experiências descritas na seqüência são partes de um projeto desenvolvido com turmas de alunos de $5^{\mathrm{a}}$ série do Ensino Fundamental, ao longo de um ano, com um período semanal, mediante um projeto de estudo da geometria através da utilização de ambiente Logo. A criança parte das relações com a sua lateralidade para fazer suas construções geométricas. 
As primeiras aulas do projeto, aproximadamente seis aulas, basearam-se em atividades lúdicas que se destinaram ao conhecimento dos seus comandos e possibilidades. O objetivo era fazer com que o aluno reconhecesse polígonos, linhas fechadas e abertas, linhas simples e não simples, representasse e nomeasse linhas planas e identificasse os elementos de um polígono - nomeando os polígonos de acordo com o número de lados e reconhecendo triângulos e quadriláteros. Além disso, as idéias de ponto, reta, plano, semi-reta foram razoavelmente compreendidas, assim como alguns elementos das figuras, como lados, arestas, vértices e faces. É importante ressaltar que tudo foi programado pelos alunos e, sendo assim, a "tartaruga" desenhou apenas o que foi explicitamente escrito em linhas de comando, isto é, o que os alunos programaram.

Um dos projetos para o fechamento do estudo sobre polígonos foi o desafio de construção de uma cidade. Os alunos tinham total liberdade para desenhar a sua cidade, desde que essa tivesse ruas, casas e edifícios, pois o objetivo era trabalhar com retas, linhas e polígonos regulares e irregulares. A Figura 1 e a Figura 2 apresentam algumas das cidades construídas. Esse projeto se desenrolou ao longo de, mais ou menos, 6 horas-aula. Os alunos utilizaram, também, efeitos de animação, com múltiplas tartarugas, em algumas cidades.
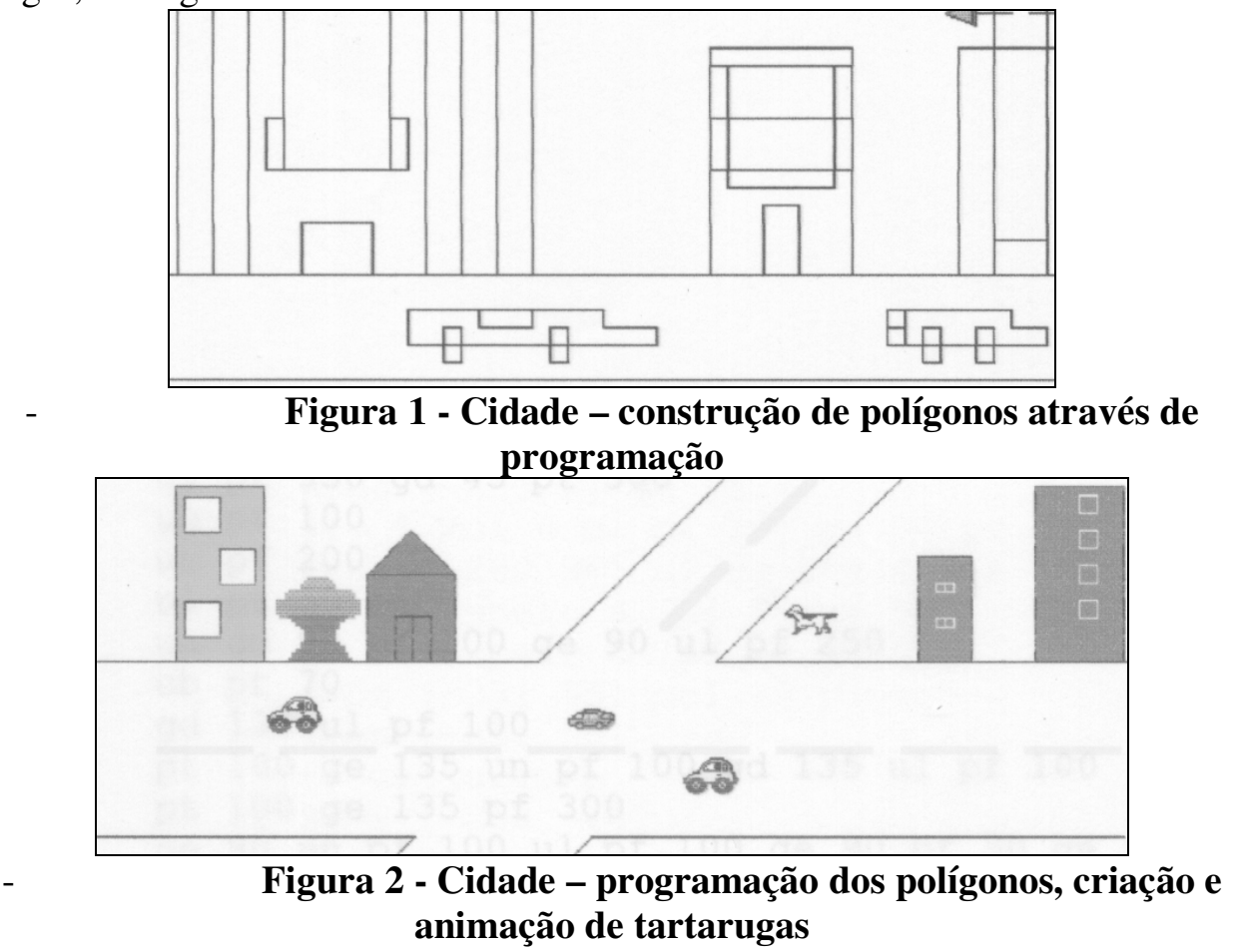

Os alunos sentiram-se motivados a desenvolver habilidades mentais, já que no ambiente Logo puderam visualizar o resultado de suas ações e, sempre que necessário, repensá-las e refazê-las. Os alunos M.W. e R.F. deram o seguinte depoimento: "Estamos aprendendo geometria com o Logo e é bem melhor, pois aprendemos na prática. É bem mais fácil. Conseguimos descobrir ângulos e fazer cálculos matemáticos. A gente se concentra mais."

A criança é a grande linguagem, o verbo, a fala do programa, porque é capaz de utilizá-lo como instrumento de encontros contextualizados e, ao mesmo tempo, interrogados em ações de brincar, refletir, brincar de novo, descobrindo o novo no próprio modo de pensar e brincar em relação aos próprios códigos que o mundo utiliza para comunicação. Por isso, acredita-se na linguagem Logo como um instrumento facilitador no estudo da geometria na $5^{\mathrm{a}}$ série. 
Com base nos projetos desenvolvidos, podem ser destacados alguns resultados: uma aprendizagem mais significativa e contextualizada; uma maior interatividade entre alunos e com o professor, já que o último é orientador/reorientador constante e a troca de conteúdos e estratégias entre os envolvidos é permanente.

\section{O Cabri-Géomètre}

\subsection{Reflexões iniciais}

O Cabri-Géomètre trata-se de um software didático para o estudo da geometria. Foi desenvolvido na França, a partir da década de 80, no Instituto de Informática e Matemática Aplicada da Universidade Joseph Fourier de Grenoble, por um grupo multidisciplinar formado por educadores, psicólogos, matemáticos e cientistas da computação. Atualmente, o Cabri é utilizado em mais de 40 países, traduzido em mais de 20 idiomas.

A palavra Cabri é, na verdade, uma sigla que representa a expressão Cahier de brouillon interactif, cuja tradução é caderno de rascunho interativo. Como o nome indica, a interatividade é a sua principal característica, permitindo a criação de objetos matemáticos na tela do computador e a manipulação direta sobre eles.

O Cabri permite construir e explorar as figuras da geometria elementar. Tudo que se faz com um lápis, régua e compasso em um papel pode ser feito no Cabri com o grande diferencial do movimento - e é esse diferencial que permite ao professor desmistificar determinados conceitos que na maioria das vezes são complicado para o aluno. Em questão de segundos, a partir de um único desenho, pode-se ter inúmeros triângulos desenhados na tela do computador (diferentes visualizações de um triângulo desenhado inicialmente e modificado de forma dinâmica), portanto pode-se explorar o que é imutável nas figuras. Não basta apenas desenhar uma figura, é preciso preservar as relações geométricas que existem. Por exemplo, pode-se desenhar um quadrado fazendo um traçado cuidadoso, verificando suas medidas, porém só será de fato um quadrado se, ao ser movimentado, continuar com as propriedades de um quadrado.

As figuras nele construídas podem ser deformadas a partir do deslocamento de seus elementos de base ou, ainda, com opções de animação, conservando-se suas propriedades. É possível marcar e medir ângulos, distâncias, áreas de superfícies e observar as alterações em tempo real, durante a manipulação dinâmica das figuras.

As possibilidades oferecidas pelo Cabri demonstram a preocupação fundamental que originou a sua concepção: auxiliar o aluno na construção do seu conhecimento. Nas atividades propostas aos alunos, no sentido de solucionar um problema, utilizando o Cabri, após a efetivação de uma construção, uma exploração da figura acontece. Isso pode levar à formulação de uma conjectura, a qual vai-se procurar verificar sobre diferentes configurações e, depois, validar (busca de um contra-exemplo) e, enfim, demonstrar formalmente [Henriques, 1999]. Os passos de construção e exploração da figura podem ser feitos no Cabri, o que levará o aluno a formular uma conjectura. A verificação e a validação dessa conjectura também podem ser feitas no Cabri.

O suporte oferecido pelo programa não só ajuda na superação dos obstáculos inerentes ao próprio processo de construção do conhecimento matemático, como pode também acelerar e enriquecer esse processo. Faz-se importante destacar, ainda, que o Cabri permite rever todos os passos utilizados pelo aluno na construção geométrica realizada, permitindo ao professor percorrer o caminho já trilhado pelo aluno e, quando houver dificuldades, identificar o ponto em que isso ocorreu e, assim, intervir apropriadamente.

As principais características do Cabri em relação ao trabalho com lápis e papel encontram-se descritas na Tabela 1 (adaptada a partir de Henriques, 1999).

\section{Tabela 1 - Cabri X Papel e Lápis}

6 - V.2 No2, Novembro, 2004 


CINTED-UFRGS
\begin{tabular}{|l|l|l|}
\hline Característica & Cabri II & Papel e Lápis Tecnologia \\
\hline Construção de figuras & Permite & Permite \\
\hline Redefinição de objetos & Permite & Não é possível \\
\hline Deformação de figuras & Permite & Não é possível \\
\hline Movimentação de figuras & Permite & Não é possível \\
\hline Validação de propriedades & Característica & Bastante limitada \\
\hline
\end{tabular}

\subsection{Experiências}

As experiências descritas aqui se referem a atividades periódicas de estudo da geometria, utilizando o software Cabri-Géomètre II, realizadas com turmas de $6^{\mathrm{a}}, 7^{\mathrm{a}}$ e $8^{\mathrm{a}}$ séries do Ensino Fundamental. Assim, buscou-se criar situações desafiadoras para que os alunos se apropriem de conceitos matemáticos aproveitando-se das possibilidades de construção e exploração que o ambiente oferece. Nesse contexto, o professor deixa de ser o entregador principal do conhecimento para assumir uma postura de colaborador no processo, fazendo intervenções e sistematizando os achados sempre que necessário.

Atividades de reconhecimento do ambiente foram realizadas no momento que os alunos foram introduzidos no Cabri. Conhecer as possibilidades existentes é importante: como desenhar um ponto (ponto sobre objeto ou sobre uma intersecção); distinguir uma reta, uma semi-reta e um segmento; desenhar um polígono regular ou não; entender como se constrói uma circunferência ou como se utiliza a ferramenta compasso; compreender o significado geométrico de uma reta paralela ou perpendicular ao perceber que, movimentando o objeto em relação ao qual tal reta foi construída, a relação de paralelismo ou de perpendicularidade se mantém; aprender a nomear os objetos; são alguns exemplos. É importante, nesse momento de reconhecimento do ambiente, estar-se atento às mensagens fornecidas pelo Cabri sempre que o ponteiro do mouse aproxima-se dos objetos desenhados. Com os alunos familiarizados, iniciaram-se os projetos.

$\mathrm{Na} 6^{\mathrm{a}}$ série, vale destacar uma série de atividades desenvolvidas com polígonos, buscando, a partir da construção e exploração dos objetos, identificar propriedades e, com a presença orientadora do professor, elaborar conceitos. Dessas atividades, a construção de polígonos a partir de uma circunferência foi bastante significativa, exigindo a utilização de retas (paralelas e perpendiculares), a marcação de pontos de intersecção e, algumas vezes, de pontos médios, o traçado de segmentos, a escolha de cores e espessuras e o uso da ferramenta que esconde objetos. Marcaram e mediram, ainda, os ângulos das figuras construídas $3)$.

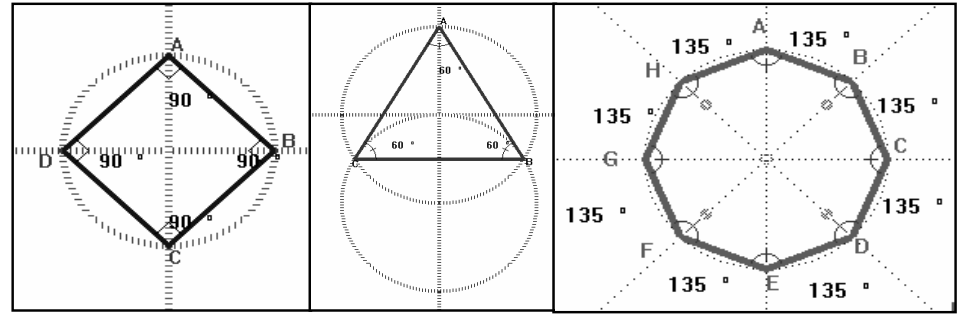

(Figura

\section{Figura 3 - Cabri - construções a partir da circunferência}

Outro trabalho a ser referenciado foi o de construção do Tangram, a partir do quadrado, de forma que quando o quadrado (objeto base da construção) fosse arrastado, ampliado ou reduzido, as relações entre as "peças" fossem mantidas.

$\mathrm{Na} 7^{\mathrm{a}}$ série, destacou-se, inicialmente, o estudo das propriedades do triângulo, como, por exemplo, o conceito de altura. A partir de construções bem elaboradas (Figura 4) e da movimentação dessas, o aluno percebe que, algumas vezes, a altura está V.2 $\mathrm{N}^{\mathrm{o}} 2$, Novembro, 2004 
fora do triângulo e, então, começa a levantar hipóteses e a testá-las, buscando construir um conceito adequado para defini-la.

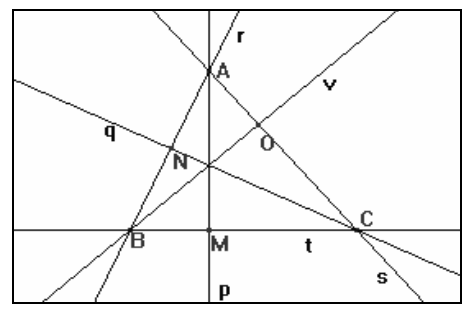

Figura 4 - Cabri - busca do conceito de altura de um triângulo

Os ângulos também foram estudados a partir de inúmeras outras construções, buscando identificar relações de congruência e complementação. A Figura 5 apresenta duas retas paralelas, cortadas por uma transversal, e a marcação e medição dos ângulos, lembrando que quando a figura é movimentada alteram-se os valores e não as relações.

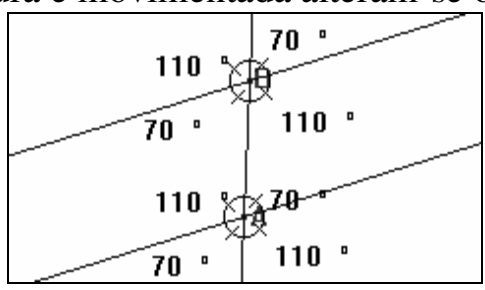

Figura 5 - Cabri: trabalho com ângulos

O trabalho que gerou mais envolvimento, no entanto, não aborda diretamente conceitos de geometria, mas trabalha com a modelagem do mundo através dela. Trata-se da criação de composições geométricas animadas, acrescentando-se o uso das ferramentas rotação e edição numérica (um elemento "gira" um "certo número de graus" em torno de um dado ponto) para a construção do desenho e, depois, da ferramenta de animação para dar movimento ao que foi realizado. A Figura 6 traz três exemplos.

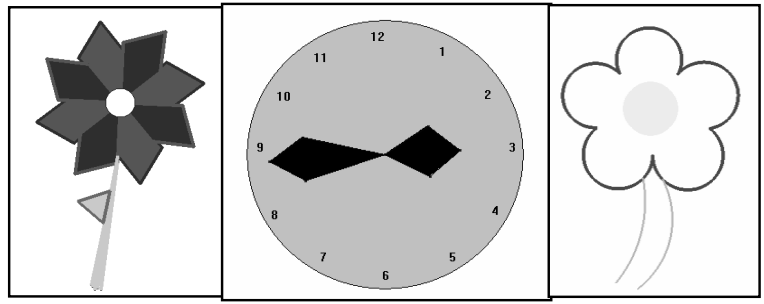

Figura 6 - Cabri - animações

$\mathrm{Na} 8^{\mathrm{a}}$ série, destacaram-se os trabalhos de ampliação de uma construção geométrica, através da ferramenta homotetia, e de redução, utilizando a marcação de pontos e a medida de distâncias (Figura 7).

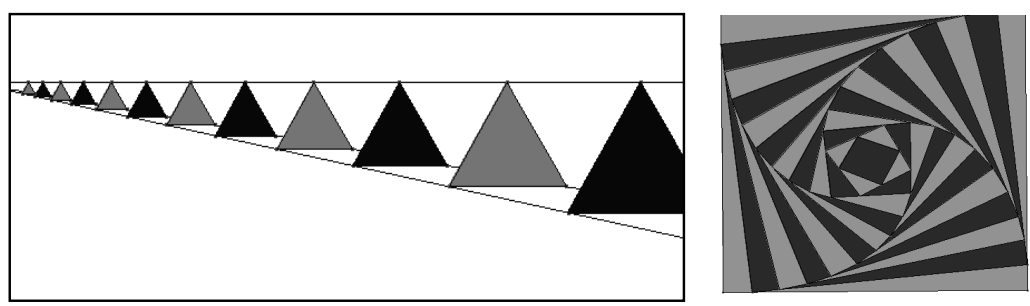

Figura 7 - Cabri: ampliação e redução

Finalizando essa seção, é importante dizer que as atividades descritas são apenas alguns exemplos dos trabalhos realizados com o auxílio do Cabri e que todas as "figuras" apresentadas são de autoria de alunos.

\section{Outros Softwares e Propostas}


Para promover uma aprendizagem mais efetiva, na área da Matemática, vários outros softwares e propostas podem, também, ser empregados. A título de ilustração, são apresentados, na continuidade, outros ambientes ou situações interessantes utilizados em experiências realizadas.

\subsection{Visualização de Gráficos / Funções}

Para a construção, visualização e exploração de gráficos, a partir de funções, há alguns softwares disponíveis, tais como o Winplot e o Graphmatica, que podem ser baixados da Internet gratuitamente, e que foram utilizados com alunos das séries finais de Ensino Fundamental e, também, com alunos de Ensino Médio.

O Graphmatica, em especial, é um software que permite trabalhar com um grande número de funções matemáticas, através de uma interface simples. Pode-se utilizá-lo para visualizar gráficos de equações algébricas, sendo possível representá-los através de vários tipos de escalas. O ambiente é configurável, permitindo a definição de cores, anotações e escalas, entre outras questões. As funções devem ser escritas de acordo com o formalismo do programa, sendo possível atribuir valores as variáveis utilizadas e gerar até 25 gráficos simultâneos, visualizando-os sobrepostos, em cores diferentes (Figura 8). Alterando os dados, gerando novos gráficos, analisando as representações geradas, os alunos podem significar conceitos, estabelecer relações e gerar novos conhecimentos.

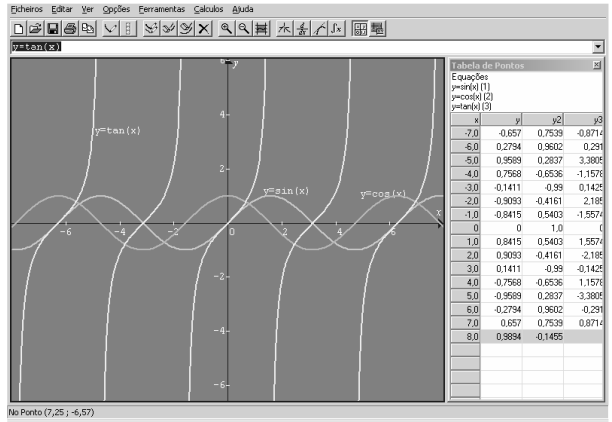

Figura 8 - Graphmatica - exemplo de gráfico

\subsection{Geometria Espacial}

São destacados, aqui, dois programas que, além de serem de fácil utilização, também são gratuitos. Tais programas foram utilizados com alunos de Ensino Médio, favorecendo a aprendizagem da geometria espacial.

O primeiro é o Lathe, para a construção e visualização de sólidos geométricos. A partir de um desenho em duas dimensões, o software gera o objeto tridimensional (Figura 9). Tal objeto pode ser visualizado em aramado ou preenchido com cores a serem escolhidas, em várias fatias, por vários ângulos, podendo-se rotacioná-lo completamente, e em escala. Além disso, pode-se ter sobre ele o efeito de uma luz (que também pode ter cores diferentes), que pode incidir no objeto a partir dos diferentes pontos distantes selecionados.

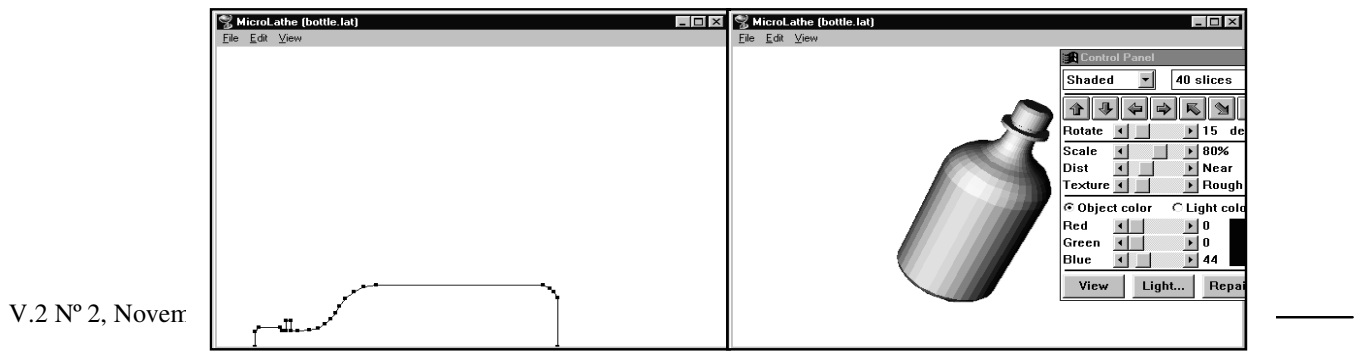


Figura 9 - Lathe - exemplo de construção de uma garrafa

O outro software é o Poly. Esse programa apresenta várias categorias de sólidos geométricos e, a partir da escolha do usuário, permite que se visualize sua superfície planificada, diretamente ou através de animação (Figura 10). Possibilita a escolha de cores e impressão.

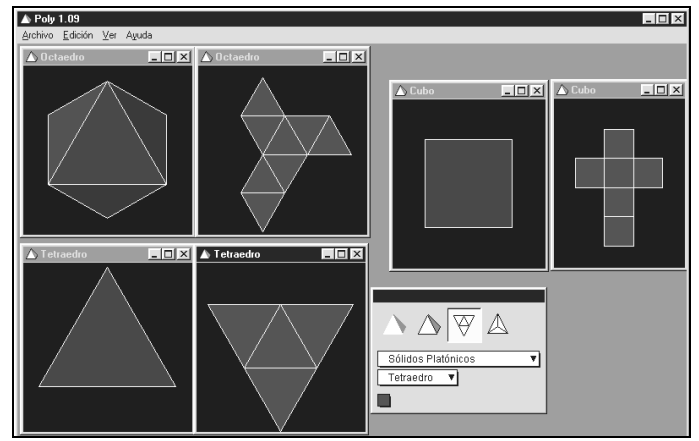

Figura 10 - Poly - exemplos de sólidos e suas planificações

\subsection{Atividades Lúdicas de Raciocínio Lógico}

Há, também, inúmeros jogos e desafios cujo objetivo é desenvolver o raciocínio lógico, devendo, então, o usuário, estabelecer estratégias para a resolução dos problemas propostos. Alguns exemplos são os jogos de encaixe de peças, as torres de Hanói, os desafios de movimentação, tais como resta um, cubo mágico, cálculos e "ratinho" (http://math.exeter.edu/rparris/winarc.html). Outros materiais interessantes, para qualquer idade, encontrados na Internet, são os desafios lógicos, tais como os propostos em http://www.plastelina.net.

Atividades lúdicas e pedagógicas, em meio digital, podem ser encontradas com relativa facilidade - cabe ao professor avaliar a relevância e o momento apropriado para oportunizá-las aos seus alunos.

\section{Conclusão}

As TICs apresentam espaços adequados ao trabalho por projetos ou mesmo para atividades lúdicas. Destacam-se a ampla gama de informações disponíveis para pesquisa; a multimídia, que proporciona ambientes com estímulos multissensoriais; e, principalmente, a interatividade e a dinamicidade que tais tecnologias oportunizam.

Construir, explorar, reconstruir - interagir para compreender, para criar novos significados a partir das situações que se apresentam. Desenvolver no aluno a observação, o questionamento e a criatividade.

Com tantos desafios, nenhum professor, nos dias de hoje, pode ignorar o uso das TICs, o papel que ocupam da sociedade e o potencial pedagógico que possuem. Cabe, então, ao educador atualizado e comprometido, buscar conhecer os diversos recursos e propostas existentes e, assim, conscientemente optar por quais instrumentos utilizar, de que forma e em que momento.

Esse artigo colabora para essa reflexão, apresentando a fundamentação embasadora, as ferramentas empregadas, as práticas realizadas e as implicações pedagógicas pertinentes ao uso das TICs na Educação Matemática.

\section{Bibliografia}

CAVEDINI, Patrícia. Informática na educação e educação física: os caminhos da interdisciplinaridade. Canoas: Ulbra, 2002. 
GRAVINA, Maria Alice; SANTAROSA, Lucila Maria Costi. "A Aprendizagem da Matemática em Ambientes Informatizados", In: Informática na Educação: Teoria e Prática - vol. 1, n. 1, 1998. Porto Alegre: UFRGS - Curso de Pós-Graduação em Informática na Educação.

PAPERT, Seymour. A máquina das crianças: repensando a escola na era da informática. Trad. Sandra Costa. Porto Alegre: Artes Médicas, 1994.

PAPERT, Seymour. Logo: computadores e educação. Tradução José A. Valente, Beatriz Bitelman, Afira V. Ripper. São Paulo: Brasiliense, 1985.

PERRENOUD, Philippe. Construir as competências desde a escola. Porto Alegre: Artes Médicas Sul, 1999.

PERRENOUD, Philippe. Dez novas competências para ensinar. Porto Alegre: Artes Médicas Sul, 2000.

VALENTE, José Armando. (1997) "O uso inteligente do computador na educação", In: Revista Pátio, ano I, n. 1, p. 19-21, Porto Alegre: Artes Médicas Sul.

VALENTE, José Armando. (1999) "Informática na educação: uma questão técnica ou pedagógica?”, In: Revista Pátio, ano 3, n. 9, p. 21-23, Porto Alegre: Artes Médicas Sul. 